Article

\title{
A Guest at Home: The Experience of Chinese Pilgrims on the Camino de Santiago
}

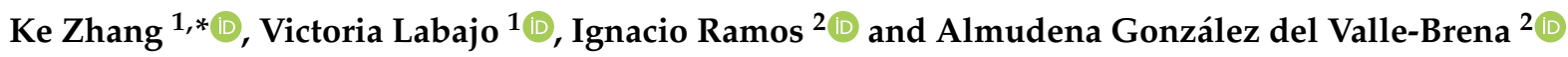 \\ 1 Faculty of Economics and Business, Universidad Pontificia Comillas, 28015 Madrid, Spain; \\ labajo@icade.comillas.edu \\ 2 Faculty of Social Sciences and Humanities, Universidad Pontificia Comillas, 28015 Madrid, Spain; \\ tachisj@comillas.edu (I.R.); agvalle@comillas.edu (A.G.d.V.-B.) \\ * Correspondence: k.zhang@comillas.edu
}

check for

updates

Citation: Zhang, K.; Labajo, V.; Ramos, I.; González del Valle-Brena, A. A Guest at Home: The Experience of Chinese Pilgrims on the Camino de Santiago. Sustainability 2021, 13, 10658. https://doi.org/10.3390/ su131910658

Academic Editors: Rubén C.

Lois-González, Rossella Moscarelli and Lucrezia Lopez

Received: 3 September 2021

Accepted: 21 September 2021

Published: 25 September 2021

Publisher's Note: MDPI stays neutral with regard to jurisdictional claims in published maps and institutional affiliations.

Copyright: (c) 2021 by the authors. Licensee MDPI, Basel, Switzerland. This article is an open access article distributed under the terms and conditions of the Creative Commons Attribution (CC BY) license (https:/ / creativecommons.org/licenses/by/ $4.0 /)$.

\begin{abstract}
This study identifies the main dimensions and attributes that shape the experience of the Camino de Santiago for Chinese travelers as a tourism product. By exploring the similarities and differences between their experiences and that of Western pilgrims, it also reflects on the sustainable marketing strategies of the Camino among Chinese travelers. The research adopts a phenomenological approach and gathers data from 112 online travel journals posted by Chinese Camino pilgrims, and from in-depth interviews with twelve Chinese pilgrims. The results reveal that the Camino is experienced by Chinese pilgrims as a personal journey of well-being and growth, as well as a cross-cultural experience. Authenticity and harmony are observed to be the key elements that contribute to a satisfying and transformative experience for Chinese pilgrims, where they find a cultural-spiritual center close to their traditional values, yet distant from their everyday social practices. Both Chinese and Western pilgrims undergo similar external and internal journeys, although each group travels in its respective sociocultural framework. The study is based on Cohen's (1979) five travel-mode theory and enriches the discussion from a cross-cultural point of view. The implications for the sustainable management of the Camino as a global cultural heritage route, and for effectively marketing it among Chinese tourists, are also discussed.
\end{abstract}

Keywords: tourist experience; Camino de Santiago; religious tourism; sacred space; Chinese tourists

\section{Introduction}

The Santiago Pilgrimage Routes, a UNESCO world heritage site, also known as the Camino de Santiago, have attracted millions of travelers a year since their revitalization in the late 20th century [1,2]. The growing multinational representation among the Camino travelers reveals the internationalization of this unique heritage tourism phenomenon as it marches into the new millennium [2]. In 2019 alone, it received more than 340,000 pilgrims from 190 different countries and regions, including 1062 from mainland China, accounting for $0.3 \%$ of the total number of pilgrims [3]. How contemporary travelers experience this millenary pilgrimage route has been capturing the attention of many scholars for over two decades. The tourist experience can be understood as the subjective interpretation of the meanings and memories created during travel-related events or while consuming tourism-related services $[4,5]$. It leaves a profound mark on the tourist's memory, wellbeing, identity, meaning-making, destination perception, satisfaction, and intention to revisit $[6,7]$.

Among many scholars of the tourist experience, Cohen [8] proposes a typology that encompasses previously conflicting views on the nature of the tourist experience and conceptualizes it as one phenomenon with varying degrees of motivations, needs, and patterns of behavior. According to the aforementioned author, the tourist experience can be understood as the experience of traveling between 'centers'. The concept of a 'center' was first raised by Eliade [9] to refer to 'the zone of the sacred and absolute reality' (p. 17). 
It was then highlighted by Turner [10] to conceptualize pilgrimage as a sacred journey towards 'the center out there', which is not necessarily in strict geographical or religious terms. The idea of such a 'center' can be multiple: it can be religious, cultural, political, or spiritual. In Cohen's conceptualization, such a 'center' is more of a spiritual locus that symbolizes ultimate meanings and values for the individual [8]. Tourists tend to either walk away from their original center, in which life is too stressful, inauthentic, or meaningless, or away from one center and towards another one. They may merely approach a new center as the goal of the trip without denying the center of their origin. Depending on how a tourist moves around different centers, Cohen [8] identifies five travel modes: the recreational mode, in which tourists desire to run away from stressful modern life and look for recreation and refreshment so that they can return to their original society with renewed energy; the diversionary mode, in which tourists simply want to run away from meaninglessness in their usual society by taking a vacation; the experiential mode, in which individuals approach and explore their own personal spiritual center; the experimental mode, in which they are not sure of their own spiritual center, and are trying out new lifestyles that represent new centers; and the existential mode, in which individuals intentionally commit to a new spiritual center that is distant from their original one. The typology focuses on tourists' personal drives and to what extent they desire to escape from the original cultural/spiritual center and seek an alternative. Cohen's typology of tourist experiences allows us to link the desires and motivations of the tourists with their behaviors. Recreational and diversionary tourists want to run away and relax. They seek a break time with pleasure and fun, and are likely to behave like tourists, engaging in hedonic mass-tourism activities. Experiential and experimental tourists travel as cultural explorers or pilgrims. They are out for authentic experiences and seek authenticity and meaning in the life of others [11,12]. Existential tourists seek higher meaning, such as human communion or union with nature. They are like new members of a culture or a religion, outside of their original sociocultural environment [8].

Given that the conceptualization of the tourist experience is highly subjective and shaped by sociocultural contexts $[4,5]$, the non-Western tourist experience should be interpreted through different cultural lenses, taking a critical distance from Anglo-Western sociological theories [4,13-15]. Most current studies focus on pilgrims from parts of the Western world, such as Europe, North America, and Oceania [16-19]. A close look at how the Camino is experienced by travelers from a non-Western background contributes to a more complete picture of the phenomena of the tourist experience on the Santiago Pilgrimage Routes, and of the tourist experience in general.

As Spain is one of the most-visited tourist destinations in the world, the entities responsible for tourism promotion in this country are striving to offer innovative and diversified tourist products to attract more high-spending tourist markets, such as China, Russia, and the USA, as one of the measures to compensate for the limitations of seasonality [20,21]. The growing importance of Chinese outbound tourism, combined with the interest in cultural and long-distance tourism, makes China one of the places with the greatest potential for outbound tourism. The global context is transforming at an unprecedented speed, weakening traditional outbound markets, with a strong and keen interest in capturing the attention of emerging markets. As a result, adaptation to the world's largest market, China, is becoming necessary [22-24]. In this context, marketing plays an essential role, beyond its promotional role, as an authentic tool for tourism territorial management [25]. To that end, understanding the travel experiences and preferences of Chinese pilgrims on the Camino can provide better information for local tourist sectors in Spain and, thus, help them to improve their management and service, increase the attractiveness of the Camino, and enhance their chances of success as an emerging destination among Chinese travelers who currently have little awareness of the Camino de Santiago.

The pilgrimage itineraries that lead to Santiago de Compostela in northern Spain, known as the Camino, can be dated back to the 9th century when the tomb of St James, one of Jesus' twelve apostles, was first discovered and visited. The pilgrimage routes were 
walked for centuries, until a decline in the 16th century. They were then revitalized in the late 20th century across Europe and beyond [1,26]. In 1987, the Santiago de Compostela Pilgrim routes were declared the first European cultural route by the Council of Europe through its cultural route program, which aims at celebrating the common memories, values, and identities of Europe, and promoting sustainable tourism [27]. The main routes and sections of the Camino were later included on the UNESCO World Heritage List of Sites [28]. With nearly three decades of rapid growth, the Camino has developed significantly and its success has resulted in an imitation of its model in other parts of the world, such as Via Francigena in Italy, and Kumano Kudo in Japan [29,30]. China is rich in cultural route heritage [31,32]. Learning from the best practice of the Camino in its revitalization could inform and inspire China in its efforts to preserve and develop the cultural routes in China.

A number of studies have researched the experiences of Camino pilgrims from a variety of disciplines, such as sociology, anthropology, psychology, and religious studies. Among these, pilgrim motivation is the most-investigated topic. Studies on thousands of Camino pilgrims, mostly of Western origin, show that the popularity of the Camino started in the late 20th century and arose from secular motives, rather than religious ones, as the majority of pilgrims made their Camino for personal reasons that may have eventually had spiritual overtones, such as a quest for meaning and life direction, as well as a desire to escape daily routines, relax in nature, or engage in sports or adventure $[2,17,19,33-36]$.

Much of the discussion about the extensive experiences of Camino pilgrims also focuses on authentic experience, personal transformation, and communion among pilgrims. Pilgrims expressed a desire for authentic experiences by welcoming the traditions of the pilgrimage route, such as carrying one's bags, walking long distances, and living under simple conditions [37-39], by running away from everyday routines [40], pursuing spiritual enlightenment and self-discovery [41], and engaging in intercultural dialogue [42]. The Camino is generally believed to be a transformative journey through which pilgrims experience a sense of freedom because the Camino allows individuals to accept the natural rhythm and limitations of the body [41,42]. The simple and slow lifestyle along the way frees people from the influence of consumerism and the pressures of modern life, such as fast-paced schedules and endless demands [40-43]. Pilgrims also reported discovering a sense of the need to update their life priorities and worldviews at the end of the journey [16-18]. With the immersion into an unstructured setting that is in contrast to their highly structured everyday lives, pilgrims are believed to be able to enter a 'liminal space' that allows change to take place $[17,44]$. 'Communitas' is a concept in anthropology, applied to the pilgrimage phenomena, that refers to the sense of communion felt by pilgrims during their pilgrimage journey $[44,45]$. Many scholars have discovered that the Camino pilgrims are able to establish an intersubjective 'communitas' among themselves by sharing common goals, life conditions, and affective experiences $[16,17,46]$.

The aim of this paper is fourfold: (1) to investigate the experience of Chinese travelers on the Camino de Santiago, and its similarities and differences with that of Western travelers in terms of motivational and experiential patterns in order to enrich the understanding of the overall pilgrim experience of the Camino; (2) to understand the experiences of Chinese Camino travelers in light of their sociocultural contexts in order to increase the understanding of the tourist experience from a non-Western perspective; (3) to identify the main attributes of the Camino as a tourist product that attracts Chinese travelers; (4) to inform more sustainable and inclusive management of the Camino as a global heritage route.

\section{Materials and Methods}

Following an interpretivist tradition, a phenomenological approach was adopted for this study to discover the experiential meaning-making process, and the underlying dynamics of the participants through their own testimony $[47,48]$.

Online tourist travel blogs have been found to be an effective material for discovering tourist motives, travel behaviors, and destination images, as tourists can freely express 
their motivations, experiences, and reflections in their blogs and journals in diverse forms, such as text, image, and music and videos, which makes such user-generated content a rich source of information for the purpose of this study [49]. Since this is the first empirical attempt to investigate the experience of Chinese travellers on the Camino, online journals posted by Chinese travellers from multiple sources were searched without any time limits on their publication dates, so that as much relevant data as possible could be collected. The most popular Chinese travel websites, such as Qyer, Mafengwo, and Ctrip, and the most popular Chinese social media platforms, Douban and Jianshu, were searched under two key terms that corresponded to 'Camino de Santiago' and 'Santiago Pilgrimage Route'. The difference is that the latter contains the word 'pilgrimage'. The first search was performed in June 2020 and the last in February 2021. The criteria for selection included: (1) the authors indicated that they had completed a Camino trip; and (2) the written account contained substantial content related to the author's personal experience on the Camino. Initial searches generated hundreds of results from various platforms, although not all were relevant. Journals about other pilgrimage routes, Camino-related movie reviews, and historical or practical information were excluded. Repeated journals were also removed. After careful screening, 112 travel journals were located, with sixty-five from Qyer, twenty-nine from Mafengwo, two from Ctrip, nine from Douban, and seven from Jianshu. The journals are systematically labelled as JR1, JR2, . . , JR112. Most journals were written in a day-to-day diary style and were posted after 2014, although the earliest ones can be dated from 2008, and the most recent ones from 2020.

The data from online journals were treated with a traditional content analysis method and theme-identifying techniques. Inductive content analysis is a method frequently used for analyzing qualitative data without a pre-existing guiding theoretical framework, which allows the researcher to look at the data with a fresh eye $[50,51]$. Nevertheless, the major topics in previous Camino pilgrim studies were taken into consideration for the purpose of comparison between Chinese and Western pilgrims. In addition to background information about the pilgrims and how they organized their Camino, the analysis generated themes, such as motivation, experience with nature, food, people, walking, accommodation, culture, etc. Those themes were further grouped into categories, such as motivation, impression of Spain, culture of the Camino, evaluation of the journey, etc.

Additional data were obtained from in-depth, semi-structured interviews with twelve Chinese travelers in order to gain more clarity and insight into the results generated from the first phase of the research. The participants must have completed the Camino but have not published journals about their journey on the websites used for data collection in this research to avoid repeating results. The participants were recruited from the Chinese Camino Friends' social media community on WeChat, an active chat group with more than 300 members (by December 2020). Using purposeful sampling, the researchers selected participants with diverse ages, genders, occupations, and religious affiliations. The participants were familiarized with the purpose of the study and were asked for their written consent to participate. The interviews were scheduled and conducted in the form of online meetings using social media during November and December 2020. As well as taking notes about demographic information and Camino travel patterns, open-ended questions were asked related to specific aspects of their experience before, during, and after the Camino journey. The questions were formulated according to the categories identified from pilgrim journal analysis, so that the data from both datasets could be merged. The interviews were recorded, transcribed, translated into English, and labelled as IN1, IN2, ... , IN12.

The data generated from the interviews were analysed with the assistance of NVIVO 1.0. This treatment consisted of separate coding among the four authors, followed by interauthor verification to increase coding reliability. An intercoder comparison indicated an agreement of approximately $90 \%$ in terms of all the codes and categories. The results from the interviews were combined with those from the previous journal analysis, and the relations between the themes and categories were explored at this stage. 


\section{Results}

\subsection{Pilgrim Profile}

The results show a group of young, urban, secular Chinese individuals walking the Camino de Santiago. As illustrated in Figure 1 and Table 1, nearly two-thirds of the Chinese pilgrims in this study were young people under the age of thirty. The working population (mostly working in China) and students (mostly studying in Europe) formed two main groups. More than a third of Chinese pilgrims came from the first-tier cities in China (i.e., Beijing, Shanghai, Guangzhou, Shenzhen). Most of them reported not adhering to any religion, and only four reported being Christian (Catholic or Protestant) across the datasets. The most popular route for Chinese pilgrims was the French Way. The majority of Chinese pilgrims travelled on foot and half of them started the journey alone. Compared to international pilgrims [3], there seemed to be more women, a younger student population, and much fewer senior and retired people among Chinese pilgrims. Both Chinese and international pilgrims chose to make their Camino mainly by walking, whereas international pilgrims tend to be more diversified in their choice of itineraries in comparison to Chinese pilgrims who are found mostly on the French Way, especially on their first Camino trip.

Many Chinese pilgrims learned for the first time about the Camino from the movie The Way (40\%), from acquaintances (28\%), and from websites $(12 \%)$, and the rest $(20 \%)$ did not disclose this information. Most Chinese pilgrims searched online for information about the itinerary, packing, accommodation, and the visa from previous pilgrims' posts on major Chinese travel websites before departure. Some also browsed the Galician official Camino website, especially those who were students based in Europe. While making this journey, those pilgrims who could read English or another Western language often used mobile applications, such as Buen Camino or Eroski, for route-related information. Some also consulted guidebooks and their pilgrim peers.

Table 1. Profile of Chinese pilgrims and international pilgrims.

\begin{tabular}{|c|c|c|c|c|}
\hline & & Number & Percentage & International Pilgrims (2019) \\
\hline \multirow[t]{2}{*}{ gender } & Male & 46 & $37 \%$ & $51 \%$ \\
\hline & Female & 78 & $63 \%$ & $49 \%$ \\
\hline \multirow[t]{3}{*}{ age } & $<30$ & 78 & $63 \%$ & $55 \%$ \\
\hline & $30-60$ & 44 & $35 \%$ & $27 \%$ \\
\hline & $>60$ & 2 & $2 \%$ & $19 \%$ \\
\hline \multirow[t]{4}{*}{ occupation } & student & 55 & $45 \%$ & $18 \%$ \\
\hline & employed & 51 & $41 \%$ & $65 \%$ \\
\hline & retired & 3 & $2 \%$ & $13 \%$ \\
\hline & $\begin{array}{l}\text { indicated/other } \\
\text { occupation }\end{array}$ & 15 & $12 \%$ & $4 \%$ \\
\hline \multirow[t]{3}{*}{ religion } & non & 114 & $92 \%$ & Not available \\
\hline & Christian & 4 & $3 \%$ & Not available \\
\hline & not indicated & 6 & $5 \%$ & Not available \\
\hline \multirow[t]{2}{*}{ route } & French Way & 94 & $76 \%$ & $55 \%$ \\
\hline & other routes & 30 & $24 \%$ & $45 \%$ \\
\hline \multirow[t]{2}{*}{ starting point } & $\begin{array}{c}\text { Saint Jean Pied } \\
\text { de Port }\end{array}$ & 36 & $29 \%$ & $10 \%$ \\
\hline & Sarria & 31 & $25 \%$ & $28 \%$ \\
\hline \multirow[t]{2}{*}{ mode } & on foot & 121 & $98 \%$ & $94 \%$ \\
\hline & bike & 3 & $2 \%$ & $6 \%$ \\
\hline \multirow[t]{2}{*}{ organization } & alone & 66 & $53 \%$ & Not available \\
\hline & $\begin{array}{c}\text { with } \\
\text { companions }\end{array}$ & 58 & $47 \%$ & Not available \\
\hline
\end{tabular}




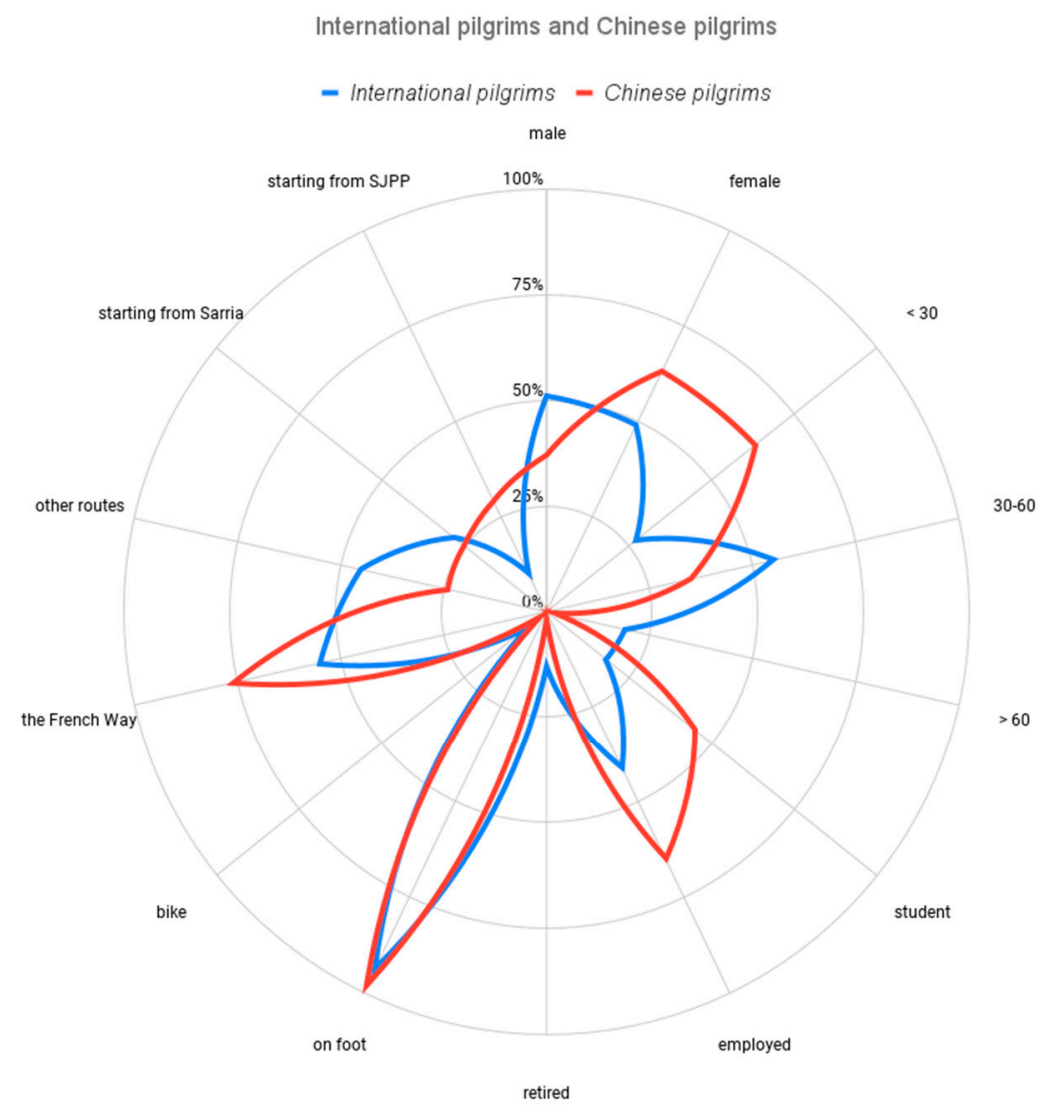

Figure 1. Profile of Chinese pilgrims and international pilgrims. Source: Authors' elaboration.

\subsection{Movitations}

Similar patterns of travel motivation were observed across datasets. More than half of Chinese pilgrims in this study (56\%) embarked on the journey mainly to promote personal well-being and growth, as an escape from stress to 'feel life', or as a quest for clarification and direction after graduation or a change of job. The second most popular motivation $(52 \%)$ was curiosity, an interest in experiencing something new, such as European cultural heritage, landscapes, or cross-cultural interactions through the Camino. Very few reported walking for sport/health or religious reasons. Four of the participants did not disclose their motivation. Two of them, both of whom were Christians, indicated that they also wanted to 'get closer to God' (JR14, IN3). A significant number of participants (37\%) stated that they decided to walk the Camino after watching the movie The Way, since this movie had impressed and inspired them with its beautiful natural scenery, fascinating cultural heritage, and touching stories of personal growth and friendship. Some of the respondents (JR6, JR40, JR62, JR76, IN8) were motivated simply by a catchy line in the movie: 'You don't choose a life, you live one'.

'I chose to walk the Camino not only because I watched the movie The Way. Most importantly it's because I wanted to stop, to ask questions about myself, to clarify doubts for myself. (JR35)

'I don't seem to have a clear goal for walking the Camino, I simply wanted to become stronger and more courageous.' (JR90)

'I was attracted by the natural landscape, the cultural landscape such as architecture, local life along the Camino presented in the movie The Way. It's like a landscape movie, but it has much spiritual elements, reflections, etc., (which leads me to make) reflections on my own present life.' (IN9) 


\subsection{Experience of Spain}

Experiences with the local people, food, culture, and natural landscape also contributed to a vivid part of Chinese pilgrims' Camino memories. Some commented that the Camino journey made them discover a different Spain from the one which had been previously known to the Chinese, limited to its iconic images of bullfighting, flamenco dancing, and Gaudís architectural heritage. The most frequent word that Chinese pilgrims used to describe the local people in general was 'warm-hearted (reqing)', and it was used particularly to describe pilgrims. Their passion and contentment with their lives, in addition to their relaxing lifestyle, all impressed Chinese pilgrims.

'When the locals give us a thumbs up, we feel incredible strength! Everyone greets us kindly and respects the pilgrims with backpacks and shells.' (IN6)

'Walking in Spain is a very comfortable experience. Besides the picturesque landscape, the relaxing and calm life attitude of the local people shows a confident universal value that can exist only after one is self-sufficient.' (JR6)

'Maybe it's under the influence of Christian views or Western customs on life and death, their cemeteries are located inside their village, their relatives can go and visit them anytime, they don't take death as a taboo like us.' (JR64)

Data from both journals and interviews provide evidence that Chinese pilgrims were very satisfied with the authentic ('yuanzhiyuanwei', meaning original flavor) local food on their Camino. Some commented that Spanish cuisine is close to Chinese cuisine in terms of flavor and ways of cooking. The majority of Chinese pilgrims reported that they admired the well-preserved cultural heritage along the Camino, such as the historical towns, churches, and cultural traditions, which contributed to the strong sense of an authentic cultural experience. Some acknowledged not being acquainted with the history and culture of Spain but showed a desire to learn more. Some stated that they had looked for an on-site introduction to better appreciate the local cultural heritage but could not find sufficient multilingual information available.

The tranquil wilderness of the Camino allowed Chinese pilgrims to enjoy not only the beauty of nature, but also a general sense of restoration, joy, and connection, and feelings of 'relaxation', 'peace', a 'return to simplicity and authenticity' (fanpuguizhen), 'liberation', 'happiness' and 'healing'.

\subsection{The Camino as a Unique Culture}

Some Chinese pilgrims pointed out that the Camino itself represents a culture characterized by a spiritual quest, a simple lifestyle, benevolent traditions, cross-cultural interactions, and unity. This culture seemed unusual and unique in contrast with their everyday social reality.

'In the mountains I encountered several times 'fruit self-service', not machines, 'selfservice' here means not supervised. Owners put out for sale their grapes, bananas, apples, oranges, packed nuts, etc, each for 1 euro, and they left a locked cash box next to it. I've never seen this in cities, I think I'll never see it. Only here on the Camino you can see something like this.' (JR103)

The volunteers at the Gaucelmo Albergue reminded me of other warm-hearted volunteers along the way, such as Grandpa Francisco, Antie Rosa, Uncle Jose Luis, etc.. The volunteers are indeed a beautiful sight of the Camino. In fact I want to thank them for their warmth and welcome to all pilgrims regardless of their cultures and backgrounds, which have allowed the Camino to become a unique, charming route of cultural diversity.' (JR73)

'The Camino stands for a lifestyle in its original and simple form: walking, carrying your own bags, living in hostels with limited conditions.' (IN2)

The experience with pilgrim peers dominates the Camino stories of Chinese pilgrims, often including detailed accounts of their observations and interactions with pilgrims of 
other nationalities. The altruism, warmth, and openness felt from fellow pilgrims deeply touched the Chinese pilgrims and fostered a sense of intimate bonding and communion. Many Chinese pilgrims used words such as 'warm', 'earnest', 'magical', 'predestined relationship (yuanfen)', 'family', and 'belonging' to describe the unforgettable moments with other pilgrims. The dynamic exchange of practical skills, cultural knowledge, and values offered Chinese pilgrims an exciting and enriching cross-cultural experience.

'A Western grandpa brought his little grandson to experience the Camino. It seems Westerners start to cultivate independence in their children at an earlier age than Easterners.' (JR63)

'It was raining in the morning when I left ... Auntie Irene from Scotland illuminated my path like an angel and reminded me from time to time about mud and puddles. I encountered all the time angels like her on the way, it has nothing to do with nationality or age.' (JR28)

'I'm very lucky that I encountered a community that's like a family: we use 'Camino family' to address each other and name our team as 'Camino legend'. We have ten young people from eight countries and five continents: we are Chinese, German, Irish, Canadian, American, French, Australian and Brazilian.' (JR54)

\subsection{Evaluation of the Pilgrimage Route}

Many Chinese pilgrim authors summarized their journey upon its completion. The interview participants were also asked to make an overall evaluation of their Camino experience. Their summaries can be classified into two types: the perceived benefits of the trip, and the attributes of the Camino. The key words and frequencies of the Chinese pilgrims' evaluation of their journey are provided in Table 2. The results across datasets show that the perceived benefits of the journey are primarily personal and psychological. 'A journey of the inner self' or 'a journey of the mind' (xinling zhi lv) are very frequent phrases that Chinese pilgrims used to summarize the Camino, by which they refer to an experience of personal well-being and growth, and of rich and profound thoughts and feelings. Chinese pilgrims seem to have been through a transformative process from which more happiness, peace, and life clarity were achieved. The Chinese word 'xinling' consists of 'xin' (heart), and 'ling' (spirit), and together they mean one's inner world in contrast to the physical world, or the mind in contrast to the physical body [52]. The Camino was seen by many as a life metaphor with its symbolic staged itineraries, uncertainties, and serendipitous events. It was also perceived as an enriching cross-cultural experience:

'Many things happened before the Camino, I was preoccupied and felt split into two: one being the body and the other the mind. On the Camino the two 'I's became one again ... I recalled what I originally intended to pursue.' (IN10)

'After those days on the way I now understand why the Camino is called a journey that touches the mind, and I come to believe that everyone can find here the meanings for the self.' (JR65)

'The Camino is truly a platform for cross-cultural communication ... This route is a get-together for the world, open your heart and you can dialogue with the world. Isn't that exciting!' (JR22)

The interview respondents were asked to specify the strengths and weaknesses of the Camino as a heritage or tourist project. The top three strengths indicated were: 'completeness of facilities' (80\%); 'well-preserved cultural heritage' (77\%); followed by 'beautiful and well-preserved natural landscape' (27\%). A major area for improvement in the eyes of Chinese pilgrims (67\%) was the lack of multilingual (Chinese in particular) information about the cultural sites along the way, which frustrated to a certain extent their interest in learning about European culture. When asked about their intention to revisit, all of the respondents stated that they would like to experience the Camino again and try a different route the next time. In fact, half of the respondents had already made their second or even third Camino by the time of the interview. 
'There are no such hiking trails in China, with supplies in every $20 \mathrm{~km}$ along the entire trail. The facilities are perfect. That's rare.' (IN8)

'It is not very commercialized and has maintained the original ecology. The preservation of natural environment and culture is very good.' (IN3)

'I had little preparation in understanding the churches. We visited some of them but didn't really understand them. If there are any stories or background history, we must have missed that.' (IN2)

Table 2. Perceptions of the Camino by Chinese pilgrims.

\begin{tabular}{|c|c|c|c|c|c|}
\hline $\begin{array}{l}\text { Key Words } \\
\text { of Benefit }\end{array}$ & $\begin{array}{c}\text { Numbers of } \\
\text { Pilgrims Who Used } \\
\text { the Key Word }\end{array}$ & $\begin{array}{l}\text { Percentage among } \\
\text { All Pilgrims }\end{array}$ & $\begin{array}{l}\text { Key Words } \\
\text { of Attribute }\end{array}$ & $\begin{array}{l}\text { Number of Pilgrims } \\
\text { Who Used the } \\
\text { Key Word }\end{array}$ & $\begin{array}{c}\text { Percentage among } \\
\text { All Pilgrims }\end{array}$ \\
\hline growth & 17 & $14 \%$ & life metaphor & 29 & $23 \%$ \\
\hline happiness & 14 & $11 \%$ & magical & 28 & $23 \%$ \\
\hline feeling touched & 10 & $8 \%$ & journey of the mind & 27 & $22 \%$ \\
\hline goodness & 9 & $7 \%$ & personal & 18 & $15 \%$ \\
\hline inner peace & 9 & $7 \%$ & worthwhile & 14 & $11 \%$ \\
\hline purity & 9 & $7 \%$ & intercultural & 14 & $11 \%$ \\
\hline warmth & 9 & $7 \%$ & unforgettable & 12 & $10 \%$ \\
\hline gratefulness & 7 & $6 \%$ & historical-cultural & 7 & $6 \%$ \\
\hline liberated & 6 & $5 \%$ & universal & 3 & $2 \%$ \\
\hline life answer & 6 & $5 \%$ & & & \\
\hline new life & 4 & $3 \%$ & & & \\
\hline rebalance & 3 & $2 \%$ & & & \\
\hline
\end{tabular}

Source: authors' elaboration.

\section{Discussion}

\subsection{Journey of Authenticity and Harmony}

The findings reveal two underlying elements reoccurring in the accounts of many Chinese pilgrims across the datasets. One of these was their experience of authenticity. Authenticity is both a core concept in tourism scholarship and a key theme in pilgrim studies of the Camino. Authenticity can be experienced in objective forms, such as the originality of historical sites and artifacts, or subjective forms, such as being true to oneself and being sincere in interpersonal relationships [11,53-55] The results indicate that Chinese pilgrims experienced both objective and subjective authenticity on the Camino. They repeatedly described how they enjoyed the 'original state' of nature, the historical monuments or traditions, and the 'original flavor' of the local food. They also emphasized how the Camino allowed them to find their 'original intention' and feel 'genuine warmth' from others.

Traditional Chinese society emphasizes norms, self-discipline, and the collective will over the individual will [56,57]. Industrialized modern life in Chinese society today is too fast-paced, competitive, superficial, and complicated, according to the pilgrims themselves. Both of these factors are present in mainstream Chinese society to a certain extent and tend to suppress the individual's experience of authenticity. In the non-Chinese, slowed-down, and simplified time and space of the Camino, authenticity is experienced extensively: through following human rhythms instead of industrial timetables; through the awareness of real needs under simple life conditions rather than materialized desires; through nonpolluted nature, a well-preserved heritage, and traditions other than commercialized, artificial attractions; through articulating one's true mind rather than having to wear social masks; through genuine interpersonal interactions with others rather than goal-oriented relationship maintenance.

Another almost ubiquitous element in the experience of Chinese pilgrims on their journey to Santiago was a sense of harmony, one of the core values in Chinese social life in the past and the present [56,58-60]. Similar experiences are also reported in the studies of Western pilgrims. Specifically, walking helps pilgrims achieve unity with the body [46]; time in the wilderness fosters harmony between self and nature [36]; engagement with the 
local culture and people facilitates a sense of connectedness with the place [41]; interactions with pilgrim peers from all over the world creates a warm memory and the sense of belonging to a 'communitas' $[16,39,45,46]$.

A harmonious relationship between man and nature (tianrenheyi) has always been one of the core values in Chinese culture [56,58]. In Daoist views, a harmonious bonding with nature is like returning home, and it cultivates restoration and healing $[59,60]$. The representation of the Camino as a 'magical' way because of the countless serendipitous encounters with others that happen along the way, as well as the frequent interpretation of such encounters as predestined relationships (yuanfen) in play, can both find their roots in Chinese folk beliefs, originally introduced from Buddhism, about the causes and timing as to when people enter or exit relationships with one another [61]. This popular view in the Chinese mindset inspires individuals to perceive new relationships in a positive light and serves as a constructive force in maintaining harmonious social relationships [62]. In Confucianism, social and interpersonal harmony is always at the heart of its teachings [56]. In short, the harmony experienced on the Camino provided a profound response to the cultural and psychological needs of Chinese pilgrims and helped them reconnect with their cultural roots $[56,58,63]$.

\subsection{Evolving Modes and Plural Centers of Travel Experience}

Cohen [8] identified five modes in which a tourist travels, from a relatively superficial escape mode to a more sophisticated transformation mode. He suggested that a tourist can travel in different modes on the same journey. This seems particularly true with regard to Chinese pilgrims on the Camino, who may start out as tourists that look forward to a break from stress and stagnation, or as explorers seeking new life experiences, but end up as cultural and spiritual pilgrims discovering a meaningful alternative lifestyle in which they can live simply but more happily. As the Camino journey progressed, the travel desires of the pilgrims also evolved, and their travel experience evolved correspondingly. Moreover, in Cohen's model, tourists travel in between 'centers' that symbolize varying sets of personal values and beliefs. For Chinese pilgrims, the Camino stands as a center of its own, and represents simplicity, balance, authenticity, harmony, and benevolence. To Chinese pilgrims, the Camino functions both as a center of 'origin' (where they come from), and of 'destination' (where they travel to). For instance, when some Chinese pilgrims experience the presence of harmony with nature, self, and others, they feel at home because both harmony and balance are very relevant in traditional Chinese culture and social life [56,58]. Thus, walking the Camino is walking towards their origin where their long-held values are alive. On the other hand, the Camino also reveals itself to be an alternative center that Chinese pilgrims approach, one which is simple, authentic, and meaningful, in contrast to the stressful mainstream Chinese society today that has been rapidly modernized and urbanized over the last few decades. In this sense, the Camino is both a homeland (because it lives out Chinese cultural ideals and values), and a foreign land (because it stands in contrast to contemporary Chinese mainstream culture), where Chinese pilgrims paradoxically feel like a guest at home.

\subsection{Similarities and Differences between Chinese and Western Pilgrims}

Most studies on Western pilgrims focus on their motivational patterns and their transformative experiences $[1,2,17-19,33-35]$. It seems that the motivational patterns of Chinese Camino pilgrims are essentially similar to those of Western pilgrims $[17,18,35,46]$, for whom personal well-being, growth, and a wish for new experiences are key motivators. However, unlike Western pilgrims, Chinese pilgrims rarely walk for reasons such as religious purpose or sport $[34,35,64]$. The lack of religious and athletic motivations among Chinese pilgrims may reflect the ideologically atheist background of the country and the relatively less popularity of sport in public life.

For both Western and Chinese pilgrims, encountering an authentic world, and experiencing an authentic self, plays a key role in their satisfaction and the transformative 
benefits of the Camino [41,65]. It seems that a journey like the Camino helps both Chinese and Western individuals find a break from the stress and the sensation of burnout caused by modern life $[16-18,36,40,43,66]$. Both groups reported having experienced a kind of re-balance, restoration and healing, achievement of clarity and direction, and a sense of meaning through in-depth inner dialogue or self-reflection [16-18,33,37-43].

However, compared to Western pilgrims, Chinese pilgrims seem to have attached greater value to their intercultural experience on the Camino, whether it involved encountering people from different countries and continents, or learning about the facts and customs of other cultures, exchanging opinions, or joining a temporary 'family of united nations', which all contributed to a sense of enrichment, fulfillment, and joy, despite some barriers, such as language and the unfamiliarity with the historical or religious background. Another characteristic observed among Chinese pilgrims was their attribution of interpersonal encounters and interactions to the wonders of predestined relationship (yuanfen).

Generally speaking, both Chinese and Western pilgrims had a satisfactory experience of the Camino and showed high intentions to revisit, which indicate that the Camino, rooted in Western-Christian traditions, has attracted fans beyond the boundaries of geography, culture, and religion. It is a globally popular destination with unique resources that allows people from diverse backgrounds to encounter and exchange with one other.

\subsection{Key Attractions of the Camino for Chinese Pilgrims}

The findings of the current study suggest that, for the Chinese pilgrims who participated, the satisfaction they derived from the Camino came not only from its natural environment, local people, culture, and infrastructure, which are common factors that lead to tourist satisfaction [67], but, in particular, from the space for personal growth and cross-cultural engagement that the Camino allows. These last two elements make the Camino stand out as unique among the other international destinations that usually attract Chinese tourists.

\subsection{Reflection on Sustainable Management of Cultural Route Heritage}

Furthermore, the findings of this study could provide specific implications for the sustainable management of a global cultural route project, such as the Camino:

(1) First and foremost, authenticity should be positioned as the most fundamental and central attribute of heritage in order to keep the Camino attractive and cherished.

(2) Multilingual information on the history, culture, and art of heritage sites along the Camino would also help Chinese pilgrims to intellectually appreciate their Camino more, e.g., by providing relevant digital information accessible through an on-site QR code, or adding images of the food on restaurant menus to improve the gastronomic experience.

(3) An inclusive approach that welcomes multicultural diversity and universal fraternity would continue to inspire and foster cross-cultural dialogue, mutual understanding, and collaboration in the face of the common challenges of the contemporary world, such as the pandemic and climate change.

\section{Conclusions}

This study reveals that the Camino is, first and foremost, a personal journey of wellbeing and growth, and then a cross-cultural journey of exchange and enrichment for Chinese pilgrims. It was a memorable experience for all of the Chinese pilgrims who participated in this study.

According to the old Chinese saying, 'different paths end in the same destination' (shututonggui), or its English equivalent, 'all roads lead to Rome', and Chinese and Western pilgrims share a lot of similar experiences on their way to Santiago, although each group's travels are conditioned by their respective sociocultural frameworks. Through the openminded exchanges and intimate relationships formed between these two groups of pilgrims 
during the journey, the Camino de Santiago route has proved itself as a perfect platform for facilitating East-West dialogue and promoting peace [68,69].

Besides the attractions of nature, people, cultural landscapes, traditions, and facilities, what impressed Chinese pilgrims the most was the unique opportunities that the Camino provided for personal growth and interpersonal and intercultural mutual enrichment. These attributes point to a clear direction for a sustainable management strategy that the Camino de Santiago should continue to follow: the preservation of the natural landscape and ecology along the routes; the protection of cultural and spiritual traditions that are unique to the Camino, including benevolence, simplicity, and welcome of diversity; the promotion of local products and services; and the good maintenance of infrastructure.

In light of the findings of this study, a more effective promotional strategy could be considered in order to increase the visibility of the Camino among Chinese travelers, taking into account the following factors:

(1) The Camino tends to be attractive to young, middle-class professionals from large cities in China and also to Chinese students living in Europe. The promotion targeted at these groups might be more effective in motivating them to experience the cultural route heritage. However, this does not rule out the possible appeal of the Camino to more general Chinese tourists who have become more diversified and experienceseeking [70], particularly among lovers of outdoor activities, religious tourists, and, perhaps, among the well-off retired population [71].

(2) Adoption of the online platforms that are most familiar to the prospective groups, such as the most popular travel websites and social media accounts used by young, middle-class professionals, or the school newsletters or cultural activity programs in European universities where Chinese students study or utilizing the networks of university professors who teach Chinese students, particularly in Spain.

(3) In addition to highlighting the natural landscape and cultural heritage, the authentic quality of the gastronomy, multicultural encounters, and the spiritual profoundness that makes the Camino experience so unique could also be featured in the promotional efforts aimed at Chinese tourists.

(4) The presentation of the Camino could be delivered through various media, including online journals and articles, books, movies, video clips, promotional conferences, exhibitions, etc., and the attention could be focused on the personal stories of pilgrims through these presentations, as this is more likely to 'wake up' the otherwise latent desires of other tourists for personal growth and intercultural experiences.

The limitations of this study lie in the possibility that younger, technologically informed subjects, along with those who felt a rich experience on the Camino, are overrepresented, since those who are not used to posting travel stories online, or those who were not impressed by their Camino experiences, might not be so easily identifiable under such an investigation. Focusing on a sample of a specific cultural group may also limit the generalizability of its findings. Another limitation is related to the retrospective nature of the interview process, which is not conducive to capturing those spontaneous and profound thoughts and feelings on the spot, unlike in many travel journals, which were written while the author was undertaking the journey. The review of previous research on the Camino pilgrim experience is also limited to the literature in the English language.

Future research efforts should be directed towards exploring the experiences of other non-Western pilgrims in light of their respective cultural contexts, the experience of local people and Western pilgrims in terms of their interactions with non-Western pilgrims, and how such cross-cultural encounters transform individuals and communities and inform the sustainable and inclusive management of global cultural routes like the Camino de Santiago. A promising line of research lays in considering how the 'best practice' of this European heritage route can cross-fertilize the preservation, management, and tourism development of Chinese cultural itineraries. Evaluations of the effects of targeted marketing strategies among Chinese tourists could also be investigated, such as in the first- and second-tier Chinese cities, or among lovers of outdoor activities in China. 
Author Contributions: Conceptualization, K.Z. and V.L.; methodology, K.Z., V.L., and A.G.d.V.-B.; software, K.Z. and I.R.; validation, V.L., I.R., and A.G.d.V.-B.; formal analysis, K.Z.; resources, K.Z.; writing—original draft preparation, K.Z.; writing—review and editing, V.L., I.R.R, and A.G.d.V.-B.; visualization, K.Z. and I.R.; supervision, V.L. and A.G.d.V.-B. All authors have read and agreed to the published version of the manuscript.

Funding: This research received no external funding.

Institutional Review Board Statement: The study was conducted according to the guidelines of the Declaration of Helsinki, and approved by the Ethics Board of Academic Committee of the Doctoral Programs of Universidad Pontificia Comillas by resolution dated on 26 May 2021.

Informed Consent Statement: Informed consent was obtained from all subjects involved in the study.

Acknowledgments: The authors wish to acknowledge the Beijing Camino International Cultural Exchange Center and the members of Chinese Camino Friends for their support of the research by recruiting interview candidates.

Conflicts of Interest: The authors declare no conflict of interest.

\section{References}

1. Murray, M. The Cultural Heritage of Pilgrim Itineraries: The Camino de Santiago. Journeys 2014, 15, 65-85. [CrossRef]

2. Lois-González, R.; Santos, X.M. Tourists and pilgrims on their way to Santiago. Motives, Caminos and final destinations. J. Tour. Cult. Chang. 2015, 13, 149-164. [CrossRef]

3. Pilgrim's Office. Available online: https://oficinadelperegrino.com/en/statistics/ (accessed on 15 December 2020).

4. Nash, D.; Smith, V.L. Anthropology and tourism. Ann. Tour. Res. 1991, 18, 12-25. [CrossRef]

5. Uriely, N. The tourist experience: Conceptual developments. Ann. Tour. Res. 2005, 32, 199-216. [CrossRef]

6. Ali, F.; Ryu, K.; Hussain, K. Influence of Experiences on Memories, Satisfaction and Behavioral Intentions: A Study of Creative Tourism. J. Trav. Tour. Mark. 2016, 33, 85-100. [CrossRef]

7. Moscardo, G. The shaping of tourist experience: The importance of stories and themes. In The Tourism and Leisure Experience: Consumer and Management Perspectives; Morgan, M., Lugosi, P., Ritchie, J.R.B., Eds.; Channel View Publications: Bristol, UK, 2010; pp. 3-26.

8. Cohen, E. A phenomenology of tourist experience. Sociology 1979, 13, 179-201. [CrossRef]

9. Eliade, M. The Myth of Eternal Return; Princeton University Press: Princeton, NJ, USA, 1971; pp. $12-17$.

10. Turner, V. The center out there: The pilgrim's goal. Hist. Relig. 1973, 12, 191-230. [CrossRef]

11. MacCannell, D. Stage authenticity: Arrangements of social space in tourist settings. Am. J. Sociolo. 1973, 79, 589-603. [CrossRef]

12. Smith, V.L. Introduction: The quest in guest. Ann. Tour. Res. 1992, 19, 1-17. [CrossRef]

13. Winter, T. Asian tourism and the retreat of anglo-western centrism in tourism theory. Curr. Issues Tour. 2009, 12, 21-31. [CrossRef]

14. Cohen, E.; Cohen, S.A. Current Sociological Theories and Issues in Tourism. Ann. Tour. Res. 2012, 39, 2177-2202. [CrossRef]

15. Jensen, Ø.; Lindberg, F.; Østergaard, P. How Can Consumer Research Contribute to increased Understanding of Tourist Experiences? A Conceptual Review. Scand. J. Hosp. Tour. 2015, 15, 9-27. [CrossRef]

16. Luik, E. Meaningful pain: Suffering and the narrative construction of pilgrimage experience on the Camino de Santiago. Suomen Antropol. J. Finn. Anthropol. Soc. 2012, 37, 24-43.

17. Lopez, L. How Long Does the Pilgrimage Tourism Experience to Santiago de Compostela Last? Int. J. Relig. Tour. Pilgr. 2013, 1, $1-14$.

18. Nilsson, M.; Tesfahuney, M. Performing the "post-secular" in Santiago de Compostela. Ann. Tour. Res. 2016, 57, 18-30. [CrossRef]

19. Amaro, S.; Antunes, A.; Henriques, C. A closer look to Santiago de Compostela's pilgrims through the lens of motivations. Tour. Manag. 2018, 64, 271-280. [CrossRef]

20. Lojo, L. Chinese tourism in Spain: An analysis of the tourism product, attractions and itineraries offered by Chinese travel agencies. Cuad. Tur. 2016, 37, 243-268. [CrossRef]

21. Medina-Muñoz, D.R.; Medina-Muñoz, R.D.; Zúñiga-Collazos, A. Tourism and Innovation in China and Spain: A Review of Innovation Research on Tourism. Tour. Econ. 2013, 19, 319-337. [CrossRef]

22. UNWTO. International Tourism Highlights, 2019 ed.; UNWTO: Madrid, Spain, 2019. [CrossRef]

23. UNWTO. International Tourism Highlights, 2020 ed.; UNWTO: Madrid, Spain, 2021. [CrossRef]

24. Croce, V. The Chinese Outbound Travel Market. European Commission. Available online: https://ecty2018.org/ready-for-china/ (accessed on 15 September 2021).

25. Majdoub, W. Analyzing cultural routes from a multidimensional perspective. Almatourism J. Tour. Cult. Territ. Dev. 2020, 1, 29-37.

26. Overall, J. The Wrong Way: An alternative critique of the Camino de Santiago. Eur. J. Tour. Res. 2019, $22,62-78$.

27. Council of Europe. The Santiago de Compostela Declaration. Available online: https://rm.coe.int/16806f57d6 (accessed on 5 May 2020). 
28. UNESCO. Routes of Santiago de Compostela: Camino Francés and Routes of Northern Spain. Available online: https://whc. unesco.org/en/list/669/ (accessed on 12 December 2020).

29. Lois-González, C.R.; Santos-Solla, X.M.; Taboada-de-Zuniga, P. New Trends in Urban and Cultural Tourism: The Model of Santiago de Compostela; Cambridge Scholars Publishing: Newcastle, UK, 2011; pp. 209-237.

30. Lopez, L.; Santos, X.M. Analysis of Territorial Development and Management Practices along the Way of St James in Galicia. In Managing Religious Tourism; Griffiths, M., Wiltshier, P., Eds.; CABI: Oxfordshire, UK, 2019; pp. 112-123.

31. Dai, X.; Li, W.; Liu, J. A study on status, features and development strategies of Chinese cultural routes. Chin. Land. Arch. 2016, 9 , 77-81.

32. Ding, Y.; Song, Y. Cultural Routes in China; China publishing Group: Beijing, China, 2015.

33. Fernandes, C.; Pimenta, E.; Gonçalves, F.; Rachao, S. A new research approach for religious tourism: The case study of the Portuguese route to Santiago. Int. J. Tour. Policy 2012, 4, 83-94. [CrossRef]

34. Oviedo, L.; De Courcier, S.; Farias, M. Rise of Pilgrims on the Camino to Santiago: Sign of Change or Religious Revival? Rev. Relig. Res. 2014, 56, 433-442. [CrossRef]

35. Farias, M.; Coleman III, T.J.; Bartlett, J.E.; Oviedo, L.; Soare, P.; Santos, T.; Bas, M.C. Atheists on the Santiago Way: Examining Motivations to Go On Pilgrimage. Sociol. Relig. A Quar. Rev. 2019, 80, 28-44. [CrossRef]

36. Kim, B.; Kim, S.S.; King, B. The sacred and the profane: Identifying pilgrim traveler value orientations using means-end theory. Tour. Manag. 2016, 56, 142-155. [CrossRef]

37. Frey, N.L. Pilgrim Stories: On and Off the Road to Santiago; University of California, Press Berkeley: Los Angeles, CA, USA, 1998.

38. Egan, K. Fumbling: A Pilgrimage Tale of Love, Grief, and Spiritual Renewal on the Camino de Santiago; Doubleday: London, UK, 2004.

39. Genoni, P. The pilgrim's progress across time: Medievalism and modernist on the road to Santiago. Stud. Travel Writ. 2011, 15, 159-181. [CrossRef]

40. Husemann, K.C.; Eckhardt, G.M. Consumer deceleration. J. Consum. Res. 2019, 45, 1142-1163. [CrossRef]

41. Carbone, F.; Corinto, G.; Malek, A. New Trends of Pilgrimage: Religion and Tourism, Authenticity and Innovation, Development and Intercultural Dialogue: Notes from the Diary of a Pilgrim of Santiago. AIMS Geosci. 2016, 2, 152-165.

42. Slavin, S. Walking as spiritual practice: The pilgrimage to Santiago de Compostela. Body Soc. 2003, 9, 82. [CrossRef]

43. Norman, A. The unexpected real: Negotiating fantasy and reality on the road to Santiago. Liter Aesthet. 2009, 19, 50-71.

44. Turner, V.W. The Ritual Process: Structure and Anti-Structure; Aldine Publishing: Chicago, IL, USA, 1969.

45. Turner, V.W.; Turner, E. Image and Pilgrimage in Christian Culture; Columbia University Press: New York, NY, USA, 1978.

46. Cazaux, F. To be a pilgrim: A contested identify on Saint James' Way. Tourism 2011, 59, 353-367.

47. Patton, M.Q. Qualitative Evaluation and Research Methods, 2nd ed.; Sage: London, UK, 1990.

48. Bryman, A.; Bell, E. Business Research Methods; Oxford University Press: Oxford, UK, 2015.

49. Carson, D. The blogosphere as a market research tool for tourism destinations: A case study of Australia's Northern Territory. J. Vacat. Mark. 2008, 14, 111-119. [CrossRef]

50. Riffe, D.; Lacy, S.; Fico, F.G. Analyzing Media Messages: Using Quantitative Content Analysis in Research; Lawrence Erlbaum: Mahwah, NJ, USA, 1998.

51. Braun, V.; Clarke, V. Using the matica nalysis in psychology. Qual.Res.Psychol. 2006, 3, 77-101.

52. Xinhua Online Chinese Dictionary. Available online: http:/ /xh.5156edu.com/html5/70211.html (accessed on 15 September 2021).

53. Cohen, E. Authenticity and Commoditization in Tourism. Ann. Tour. Res. 1988, 15, 371-386. [CrossRef]

54. Wang, N. Rethinking authenticity in tourism experience. Ann. Tour. Res. 1999, 27, 835-862. [CrossRef]

55. Cohen, E. 'Authenticity' in tourism studies: Aprés la lutte. Tour. Recreat. Res. 2007, 32, 75-82.

56. Guo, C. Tourism and the spiritual philosophies of the 'Orient'. In Tourism, Religion and Spiritual Journeys; Timothy, D.J., Olsen, D.H., Eds.; Routledge: New York, NY, USA, 2006; pp. 121-138.

57. Huo, J. Discussion on Confucian Self-Cultivation and Buddhist Practice. J. Xi'an Shiyou Univ. 2020, $29,80-86$.

58. Jiang, S.; Scott, N.; Tao, L.; Ding, P. Chinese tourists' motivation and their relationship to cultural values. Anatolia 2018, 30, 90-102. [CrossRef]

59. Wang, J.; Stringer, L.A. The Impact of Taoism on Chinese Leisure. World Leis. J. 2000, 42, 33-41. [CrossRef]

60. Qing, X. The position and modern value of Taoism in Chinese traditional cultural. J. Hunan Univ. 2006, $20,5-13$.

61. Bai, H. Analysing the Cultural Meaning of 'yuan' and 'yuanfen'. Nankai Linguist. 2004, 1, 125-133.

62. Zhao, J.; Zuo, B. Contextual Incidents, Interpersonal Orientation and Interpersonal Satisfaction. Psychol. Explor. 2008, 28, 88-92, 96.

63. Pearce, P.L.; Wu, M.; Osmond, A. Puzzles in Understanding Chinese Tourist Behavior: Towards a Triple-C Gaze. Tour. Recreat. Res. 2013, 38, 145-157.

64. Schnell, T.; Pali, S. Pilgrimage today: The meaning- making potential of ritual. Ment. Health Relig. Cult. 2013, 16, 887-902. [CrossRef]

65. Blom, T.; Nilsson, M.; Santos, X. The way to Santiago beyond Santiago. Fisterra and the pilgrimage's post-secular meaning. Eur. J. Tour. Res. 2016, 12, 133-146.

66. Barlar, S.H. Modern Influences along an Ancient Way: Pilgrimage and Globalization. In Pilgrimage as Transformative Process; Warfield, H.A., Hetherington, K., Eds.; Brill: Leidon, The Netherlands; Rodopi: Boston, MA, USA, 2018; pp. 89-96.

67. Laws, E. Tourist Destination Management: Issues, Analysis and Policies; Routledge: New York, NY, USA, 1995. 
68. Tilson, D.J. Religious-spiritual tourism and promotional campaigning: A church-state partnership for St. James and Spain. J. Hosp. Leis. Mark. 2005, 12, 9-40. [CrossRef]

69. Ramos-Riera, I. Proyección de las Rutas Compostelanas en China. Available online: https://www.mundiario.com/articulo/ claves-de-china/proyeccion-rutas-compostelanas-china/20210324204410215309.html (accessed on 15 September 2021).

70. UNWTO. Guidelines for the Success in the Chinese Outbound Tourism Market; UNWTO: Madrid, Spain, 2019. [CrossRef]

71. Bao, J.; Jin, X.; Weaver, D. Profiling the elite middle-age Chinese outbound travelers: A 3rd wave? Cur. Issues Tour. 2019, 22, 561-574. [CrossRef] 